\title{
The domestic ecology of Australian subscription video on demand services
}

2015 was a banner year for Australian consumers of screen media content, largely because several subscription video on demand (SVOD) platforms launched in the country. The most notable market entrant was the SVOD behemoth Netflix. However, Fairfax Media and Channel Nine-financed local SVOD service Stan also entered the market and existing SVOD service Presto (financed by Foxtel and Seven West Media) began to offer television shows alongside their collection of films in the same year. ${ }^{1}$ These market entrants sat alongside ondemand free to air (FTA) content that was being made available on a range of networkcontrolled applications as well as Quickflix, Fetch TV, T-Box and Apple TV (Herd, 2016). Australians who had long struggled with the 'tyranny of digital distance' (Leaver, 2008) suddenly had access to a wealth of on-demand screen content that could be accessed at a comparatively cheap price or - in the case of FTA content - for free.

This was a significant shift for a country that had long been colloquially referred to as one of the global leaders in online piracy. For a number of years Australians had been enthusiastically downloading movies and television shows (see Dootson and Suzor, 2015; Leaver, 2008; MacNeill, 2016; Lobato and Meese, 2016). Some of this downloading was no doubt motivated by opportunism (i.e. the ability to access content for free). However, the simple issue of access also drove people, particularly when it came to watching television. Australians were (and in some cases still are) regularly subject to significant delays around television programming and have to avoid spoilers that circulate in fan communities and are published in domestic and international news (Leaver, 2008). Australian fans eventually got sick of waiting and started to download shows from peer to peer networks immediately after

\footnotetext{
${ }^{1}$ At time of writing it appears that Presto will soon cease to exist (Simpson, 2016). In other developments, the free-to-air consortium freeview are planning on launching a centralised mobile app for FTA content (Reilly, 2016).
} 
their favoured (often U.S. or U.K. based) shows aired (Leaver, 2008). In recent years, people also turned to cyberlockers (Lobato and Tang, 2014), illegal streaming sites (Meese and Podkalicka, 2016; Hoof, 2016) and circumvention tools like Virtual Private Networks, that allowed Australians to access (and pay for) platforms like Netflix that had yet to launch in Australia (Dootson and Suzor, 2015; Lobato and Meese, 2016). While some consumers turned to new commercial endeavours like the iTunes store, the inequitable pricing of digital goods in comparison to other nations arguably affected its ability to make inroads in the Australian market (see House of Representatives Standing Committee on Infrastructure and Communications, 2013).

Therefore, the fact that most of the commercial streaming platforms available in Australia only launched recently is significant. A range of media content that was difficult to access without resorting to online copyright infringement was suddenly made available. Furthermore, screen content that previously could only be purchased individually through intermediaries like Apple's iTunes store was now incorporated into a seemingly limitless content buffet where consumers could orient their purchasing around content access rather than ownership. Considering the chequered past of Australian film and television consumers, the obvious question to ask is whether the launch of these services has significantly altered the habits of individuals who engage in online copyright infringement or use circumvention tools? This article tackles this question from a broader perspective, by building on previous work that has explored media practices and the domestication of media in the home (Church et al., 2010; Haddon, 2007; Kennedy, 2015; Lally, 2002; Nansen, 2009; Silverstone, 1994). Drawing on a series of in-depth semi-structured group interviews conducted with nine households in Melbourne and Sydney across 2016, I show how subscription SVOD has 
embedded itself in the routines and habits of Australians and the existing media ecologies of their homes.

\section{The domestic sphere and copyright infringement}

A notable amount of research has been conducted on the domestication of media, where scholars examine how media gradually becomes embedded in the everyday routines and habits of individuals and households (see Haddon 2007; Silverstone and Hirsch, 2003). This work has predominantly focused on the household due to the fact that this is where media was 'mostly experienced, especially television' (Haddon, 2007 p. 28). From this point of departure, researchers have explored the introduction of specific technologies to the home environment (Lally, 2002) and have addressed how media is experienced in the home more generally (Church et al. 2010; Nansen et al. 2009; Silverstone and Hirsch, 2003). Considering this focus on household routine and habits, it should come as no surprise that the notion of practice has become a central concern for these scholars, allowing them to treat these everyday engagements with media as 'central objects of analysis [that] have a bearing on the constitution of natural and social worlds' (Kennedy et al., 2016, p. 147; also see Bourdieu, 1984).

Domestication research also contends that the introduction of media objects and technologies into households can be significant. Elaine Lally (2002, p. 29) notes that our 'personal possessions and the routine activities of our everyday lives become $[\ldots]$ the anchors for our personal place in the world'. It therefore follows that deciding to purchase SVOD can not only alter people's everyday activities but can affect how people imagine themselves (Lally, 2002), their homes (Church et al. 2014) and their relationship with wider economic and market structures (Silverstone 1991). Kate Church and others (Church et al. 2014, p. 280) 
have shown how changing media practices in the Australian home have altered the constitution of households, with people reconfiguring their home 'structurally, aesthetically, and perhaps even definitionally'. That being said, Elizabeth Shove and Mika Pantzar (2005, p. 61) remind us of the need contextualise the changes wrought by new media technologies, noting that 'new practices' largely 'consist of new configurations of existing elements or of new elements in conjunction with those that already exist'. In short, innovation in terms of technologies and the practices surrounding them does not emerge out of nowhere but is instead shaped by how 'constituent elements fit together' (Shove and Pantzar 2005, p. 61).

Existing scholarly and industry research provides us with some general insight around the uptake of streaming media in Australia. Consumer group Choice noted that prior to the introduction of Netflix in Australia, over 684,000 Australians were accessing overseas streaming media through the use of circumvention tools (Bird 2014; see also Given, 2016). A recent survey of Australian Internet users also revealed that $20 \%$ of respondents either used 'a VPN, a proxy service or both' to access the Internet, with many respondents no doubt using these services to access geo-blocked media (Lobato and Ewing, 2014). However, several Australians also subscribed to the Australian version of Netflix, Stan and/or Presto following their local launches (Roy Morgan Research, 2016).

In short, these statistics give us some sense of how Australians are engaging with streaming screen media at a macro-level. There has been an ostensible drop in online copyright infringement, some level of familiarity with VPNs and a willingness to subscribe to pay for streaming video subscription services. However, they do not tell us about how people use these services at the level of the household, about the process of domestication that these services go through, or about what practices these services supplement or replace. By 
exploring how Netflix and other SVOD services enter the home and asking households about their streaming media use we will be able to assess the impact of streaming media in the Australian home and further our understanding of how streaming media practices intersect with existing practices of copyright infringement and VPN use.

\section{Methods: talking about streaming media in the home, at home.}

This project draws on data that was generated through group interviews across 2016 with nine households from Melbourne and Sydney, consisting of either couples living together or two single people living together in a shared house. The residents were current users of at least one SVOD service and at least one member of the household had engaged in copyright infringement in the past. All eighteen participants have been given pseudonyms.

\begin{tabular}{|c|c|c|}
\hline Pseudonyms & Location & Household Size \\
\hline Tracy and Scott & Melbourne & 2 \\
\hline Abigail and Daniel & Melbourne & 2 \\
\hline Markus and Amanda & Melbourne & 2 \\
\hline Simone and Oliver & Melbourne & 2 \\
\hline Damien and Astrid & Sydney & 2 \\
\hline Lucas and Georgie & Sydney & 2 \\
\hline Matthew and Ella & Sydney & 2 \\
\hline Francis and Anna & Sydney & 2 \\
\hline Victor and Lucy & Sydney & \\
\hline
\end{tabular}


Participants were recruited through convenience sampling and it was only through chance that only smaller households responded. However, the results of this sampling process meant that findings cannot be said to be representative of how the introduction of SVOD services has played out for Australia at large. In particular, the study cannot make any real claims about how habits and practices around streaming play out in the context of larger households or households with children. However, the data that was generated produced a strong body of themes that were identifiable across the interviews and the sample stands as an illustrative geographically bounded selection of 'early adopters', who have signed up to these new subscription services. Collection stopped once thematic saturation was reached. Data was also gathered with a view to timeliness. With 2015 standing as a transformative year in terms of Australian access to authorised streaming content, the goal of this project was to capture early accounts of this transition by talking with households while the transition was still fresh in their minds.

It is also worthwhile contextualising reflecting on this methodology in the context of the wider debate around online copyright infringement. While qualitative research has been conducted around post-broadcast consumption (Pertierra and Turner 2013; Turner and Tay 2009), there is still a lack of independent qualitative evidence around copyright infringement. Existing industry-funded, government and scholarly research around piracy has involved large-scale survey work (see Ewing et al. 2014; Larsson et al. 2014; Online Copyright Infringement Research, 2015; 2016). ${ }^{2}$ This gives us a broad picture of the levels of infringement in Australia but cannot account for the everyday and habitual decisions around media consumption that shape these practices.

\footnotetext{
${ }^{2}$ The Creative Content Australia (formerly Intellectual Property Awareness Foundation) also conducts annual surveys in this fashion. See http://www.creativecontentaustralia.org.au/research/2015
} 
Furthermore, one of the few detailed and rigorous qualitative studies of Australian consumers views on infringement was conducted prior to the introduction to Netflix (Dootson and Suzor, 2015). This study found that 'one of the major reasons that Australians seek out illicit downloads [...] is that it is more difficult to access [content] legitimately in Australia' (Dootson and Suzor 2015, p. 207). It also posited Netflix, which was not yet available, as an ideal example of the type of streaming services that Australia should cultivate in order to bring down rates of infringement (Dootson and Suzor, 2015, p. 214). Therefore, the data outlined in this paper can contribute to this growing body of independent qualitative research around infringement by exploring whether this 'Netflix effect' (as well as the broader vista of SVOD services now available to Australians) has supplanted or merely supplemented copyright infringement as well as address how these changes in the SVOD sector affect VPN use. Moreover, by discussing these changes with households, the study also offers a highly contextual account of how decisions around whether to access content in an authorised or unauthorised fashion are made in the home and their impact on the constitution of the home itself.

The access solution: From infringement and choice to curation and casual consumption

The central finding from these interviews was that access to streaming media caused participants to engage in less copyright infringement. All of the households noted that while they previously had downloaded music, films or television shows in the past, they found that SVOD services like Netflix had caused them to change their consumption habits. Markus explained that while he and his partner Amanda (personal interview, 23 ${ }^{\text {rd }}$ April 2016) 'used to BitTorrent a lot more [...] most of the time we watch Netflix', and this response was common amongst participants. In a similar fashion, another couple Lucas and Georgie stated 
that they 'haven't downloaded something illegally for quite a long time' (personal interview, $31^{\text {st }}$ August 2016). However, this shift from illegal to legal forms of consumption was not an easy transition for participants but rather one that was tied up in a collective ongoing assessment around two critical factors: ease of access and the question of quality.

Simone and Oliver had only subscribed to Netflix recently and mentioned that one motivation for signing up was that engaging in online copyright infringement took too much time. They explained that they 'got sick of waiting for things to download' (Simone and Oliver, personal interview, $27^{\text {th }}$ March 2016) and walked me through their previous routine of downloading and the steps involved:

Oliver: We don't have a lot of time because we probably don't get home most days until 7:30 [pm] and we try and go to bed by 10:30 [pm] [...] If you go, all right let's watch a 45 minute or an hour episode. If it takes you half an hour to find it, download it-

Simone: Then wait for the download.

Oliver: Then that's a two-hour process to watch a show rather than a 1 hour process. (Simone and Oliver, personal interview, 27 ${ }^{\text {th }}$ March 2016)

In contrast, they felt that Netflix offered them a simple and easy method through which to access content and watch it quickly. Markus also explained that he and Amanda preferred to watch Netflix rather than torrent something as it was 'less of a hassle' (personal interview, $23^{\text {rd }}$ April 2016). Daniel (Abigail and Daniel, personal interview, $28^{\text {th }}$ April 2016), a 
participant in another household, framed it as an absence of choice, stating that Netflix's curation made it a much easier process than 'sitting down with someone where you were just going to like download anything [...] it's horrible to find what you're going to watch'.

Indeed, ease of access was such an important issue for participants that many had altered their viewing habits to better match with what was available on Netflix's catalogue. A strong consumer rights discourse has been a feature of Australia's debate around online copyright infringement, with a vocal section of the population continuing to download copyright infringing material because they wanted the freedom to watch specific programmes at a time that suited them (see Lobato and Meese, 2016). When Netflix launched for example, there was a debate around whether it would be successful since it had a much smaller catalogue than its U.S. counterpart. However, the ability to access screen content quickly and easily changed the behaviour of these participants. They became satisfied with what Netflix and other SVOD services had on offer. For example, Abigail noted that Netflix 'forms my viewing habits about what content I do view' and her partner David agreed, explaining that 'you just like kind of take what you're given because that's good enough' (personal interview, $28^{\text {th }}$ April 2016). Tracy, from another household, supported this point noting that she used to download content illegally but then stopped once she got Netflix and will now just watch 'whatever is on Netflix' (Tracy and Scott, personal interview, 24 ${ }^{\text {th }}$ April 2016).

Interviewees also contextualised this shift towards legal content in terms of the quality, with one participant Scott noting that foreign films were much easier to watch on Netflix than on illegal streaming sites. He explained that on these sites 'the language and the subtitles will be really bad' and Netflix was a significant step up in quality (Tracy and Scott, personal interview, $24^{\text {th }}$ April 2016). Abigail also made a similar point. When she followed Ice 
Hockey she preferred to pay to stream the National Hockey League because (NHL) of convenience and quality (Abigail and Daniel, personal interview, $28^{\text {th }}$ April 2016). Not only were illegal streams hard to find but the games were poor quality and the wrong commentary track was often playing (Abigail and Daniel, personal interview, 28 $8^{\text {th }}$ April 2016).

As noted, at least one participant in each household had infringed copyright themselves and asking after the destination of this infringing media provided some insight into why streaming media may have been so successful amongst the participant group. Participants largely treated pirated film and television content as essentially disposable with many stating that when they used to download television shows (for example) they would simply 'watch them' and then 'delete them' (Tracy and Scott, personal interview, 24 ${ }^{\text {th }}$ April 2016). All households either failed to keep an archive of infringing screen content, had kept it and subsequently lost it (due to hard drive failure) or had an archive but never used it. This absence of an active archive suggests that the participants were already primed for streaming culture with many people effectively 'streaming' screen content but through a more laborious method of downloading and then disposing of content.

This turn to legality was often not entirely complete. While participants stated that they had stopped downloading sound content, many qualified this statement later on in the interview explaining that they could not renounce copyright infringement entirely, particularly when it came to television and film. One household noted that they engaged in this practice to access 'specific shows' and immediately qualified this statement by saying they'd 'prefer not to' (Matthew and Ella, personal interview, 31st July 2016). Another household explained that there 'were two or three movies that we have downloaded just because they're not available' and framed them as 'rarities' and 'stuff that slips through the cracks', which would not be 
accessible through commercial means (Anna and Francis, personal interview, $2^{\text {nd }}$ of October 2016). However, these activities were presented as aberrations to their habitual practice and all households interviewed preferred to access most their content through legal means. It is also worth noting that this finding has been replicated at a larger scale with a recent representative survey from the Department of Communications (2016) finding that copyright infringement had dropped in Australia following Netflix's introduction, which strongly suggests that similar dynamics of consumption are playing out in a significant portion of Australian homes.

\section{Extending access: using and understanding circumvention tools}

The introduction of SVOD in these households changed practices around infringement dramatically. However, the use of circumvention tools to access geoblocked content complicated this picture. Only three households had signed up to Netflix following the Australian launch and they did not use circumvention tools (although one household experimented with using a VPN but had difficulties using it and stopped). In contrast, six households originally signed up to U.S. Netflix prior to 2015 and were continuing to move across different regional libraries with a VPN or a Smart DNS proxy. ${ }^{3}$ The major difference between these households was the presence of at least one individual with a strong level of digital literacy in the household.

Rather than VPNs and Smart DNS functioning as a household tool to be used by all members, there was usually one individual in each house who managed the service and

\footnotetext{
${ }^{3} \mathrm{~A}$ VPN can circumvent geoblocking and encrypts Internet data whereas a Smart DNS proxy can only be used for circumvention purposes.
} 
deployed it when necessary, with this 'digital housekeeping [... cluster[ing] unevenly in particular individuals' (Kennedy et al., 2016, p. 419). All the six households who used these technologies featured one person who carried an easy familiarity with technology. The presence of an individual in the household who could use the affordances of a VPNs or a Smart DNS proxy changed how this subset of participants engaged with SVOD services. Out of these six households, three of the households logged into Australian Netflix as their default service whereas the other three used U.S. Netflix as their default. However, in all cases when households wanted to watch a show they would travel the globe and access libraries from the U.S., the U.K., Canada and even Brazil. They would also search out geo-blocked streaming services that were available in other countries such as Hulu and BBC iPlayer.

Moving Netflix libraries or accessing alternative streaming services was a strategic practice with participants moving countries for particular shows rather than just moving to see what was there. Geoevasion was also a complicated practice and every household with a circumvention device were dealing with a number of issues associated with the use of these tools. Daniel explained that he deliberately used a Smart DNS because VPNs generally slowed down Internet traffic (Abigail and Daniel, personal interview, 28 ${ }^{\text {th }}$ April 2016). Other participants who used VPNs supported this view but kept using VPNs because they felt they could manage its impact on their internet speeds strategically. They would turn it on when they wanted to circumvent geoblocking and then turn it off again after they had finished watching the movie or television show so they could browse at a faster speed. Participants also stated that Netflix had recently started to block their circumvention attempts. While these participants spoke about the convenience of Netflix as a reason for stopping copyright infringement, many were happy to fight back against the inconvenience of this blocking, reshaping their domestic media ecology in order to regain the ability to circumvent 
geoblocking. For example Daniel explained that their DNS proxy will 'generally [...] will work through a laptop so we're kind of moving away from chromecasting ${ }^{4}$ to [a] laptop [with a HDMI cable to the] TV to watch video' (Abigail and Daniel, personal interview, $28^{\text {th }}$ April 2016) and Markus, who was both curious and technologically adept built his own VPN as a way of regaining his circumvention ability (Markus and Amanda, personal interview, $23^{\text {rd }}$ April 2016).

It is worth reflecting on these practices in light of the earlier discussion around online copyright infringement. The willingness of participants to continue finding ways to circumvent geoblocking stands in stark contrast to the disavowal of their previous copyright infringement or the apologetic excuses for continuing to infringe. Indeed, the occasional participant claimed that circumventing geoblocking was more acceptable than copyright infringement and clearly articulated a moral rationale for doing so:

My preference is that I want to pay for it and I will blur lines internationally to pay for it, if there's something that's not available to me in my country, then I'm going to pay for it from another country, rather than downloading it (Astrid, personal interview, $26^{\text {th }}$ October 2016).

However, while people wanted to be able to circumvent geoblocking and felt they had the right to do so, the actual practice of circumvention was not always commonplace. While four of the six households were regularly engaging with overseas libraries (Francis and Anna, Victor and Lucy, Tracey and Scott, Abigail and Daniel), others viewed circumvention as an optional bonus rather than a sustained media practice (Markus and Amanda, Matthew and

\footnotetext{
${ }^{4}$ Chromecast is a device produced by Google that allows people to 'cast' content from their digital devices to their television, which allows people to watch over-the-top services like Netflix on television.
} 
Ella). For example, Markus and Amanda only 'jumped to the US library' once 'in the last month or two' (Markus and Amanda, personal interview, $23^{\text {rd }}$ April 2016). This suggests that while VPN tools are present in a significant minority of Australian homes (Lobato and Ewing, 2014), it cannot be assumed that all are regularly being used to circumvent geoblocking, although that may be the ideal use case.

These findings also shed light on the other main affordance of the VPN, its ability to encrypt Internet traffic (see Lobato and Meese, 2016b). Only a few individual participants (as opposed to households as a collective) were vocal about the importance of Internet privacy, with Matthew explaining that he introduced a VPN into the household for "privacy and security reasons' (Matthew and Ella, personal interview, 31st July 2016) and Markus stating that one reason he chose his VPN provider was because it was the 'most reputable in terms of protecting their customer's privacy' (Markus and Amanda, personal interview, $23^{\text {rd }}$ April 2016). However, these two participants acknowledged that they used their VPNs in ways that did not always support their goal of privacy protection. While Matthew had a VPN running constantly on one computer, another VPN was turned on and off strategically and Markus noted that the household 'haven't really used it for blanket use yet' no doubt keeping in mind the affect that VPNs have on internet speeds already noted above (Markus and Amanda, personal interview, $23^{\text {rd }}$ April 2016). These responses show how technological limitations can affect how regularly privacy conscious citizens use VPNs and suggests that while encryption may be a central reason for purchasing a VPN, the VPN may not be used consistently in a privacy conscious fashion.

\section{The resilience of the box in the corner}


We have seen how various routines and habits around television consumption have altered following the introduction of legal streaming media into the home. However, interviewees argued that while their habits had changed, these new services did not fundamentally change the experience of watching television at home. While streaming media services offer the opportunity to watch content from a range of devices, when asked to describe their average night of screen consumption after coming home from work, all of the households still preferred to turn on a television in the corner to access streaming media services. As Francis and Anna explained, the reasons for this are relatively obvious:

Francis: We just use the TV ...

Interviewer: What are some of the reasons for staying in the lounge room area...?

Anna: The TV is very large. The lounge is very comfortable [...] How can they see anything that is going on that screen (referring to people who watch streaming media on laptops or smaller devices) (Anna and Francis, personal interview, $2^{\text {nd }}$ of October 2016)?

That being said, following further discussion it gradually became clear that the greater personalisation and mobility that streaming media provides were used by participants at specific points.

Over the course of the interview, households presented a timeline of consumption that looked like the one offered by Abigail below: 
There's like watching TV on the TV, and then, like, I guess generally night or in the evening, we'll like go to bed and then perhaps watch something different, both of us on the laptop, maybe Netflix or maybe like YouTube or something like that (Abigail and Daniel, personal interview, $28^{\text {th }}$ April 2016).

While the television was retained for shared viewing and as the night wore on people would eventually turn to mobile devices in order to watch television that matched their individual interests.

It is also important to note that participants' initial description of streaming media's seamless introduction into the traditional living room did not immediately acknowledge the organisation that had been undertaken to embed this new technology into their domestic media ecology. At a basic level, participants used a range of technologies from Chromecasts and PlayStations to Smart TVs and laptops connected with HDMI cables in order to access streaming media services. Furthermore, as we saw above, a subset of these participants also sourced VPNs or Smart DNS proxies in order to enhance their streaming experience and often this ecology was altered in order to retain the ability to circumvent geoblocking. The purchase of a Chromecast (a relatively cheap piece of technology) is not a significant thing, but it does show that these domestic media ecologies are altered and subsequently normalised through habitual use like the process outlined by Shove and Pantzar (2005) earlier. Of course the participants' description of legal streaming as easier than copyright infringement still rings true, but there is still clear effort involved in accessing these services, particularly if one wants to continue to access geoblocked media.

\section{Conclusion}


This article has briefly presented early findings from research examining the introduction of legal streaming media into the lives and homes of Australians. Data drawn from group interviews conducted with nine Australian households shows that these services have made a significant impact on how people access content, with respondents preferring to use these services rather than infringe copyright, a finding that has been subsequently supported by larger representative surveys. Connections in the sample were also drawn between VPN and Smart DNS usage and households that had a resident with a significant level of digital literacy. It was also found that households with circumvention tools used them in a haphazard fashion. Finally, while participants made use of the mobile and personalised nature of these streaming media services, televisions still maintained their prominence in the home and communal viewing was self-identified as a predominant practice in households. These latter findings could all be productively explored in sustained ethnographic studies of households.

In addition, to the relatively functional findings above, I also want to briefly reflect on how this research fits within the broader trajectory of domestication research outlined earlier, particularly the work of Roger Silverstone, Eric Hirsch and David Morley (2003), and argue for its ongoing importance today. Silverstone, Hirsch and Morley argued that the household had its own "moral economy" that could function through a substantially different set of economic values "from those that operate in the market and the public sphere" (Silverstone et al., 2003, p.18). This work reminds us that the household is an "economic unit" where everyday practices, like the ones detailed throughout this article, also function as "a process of value creation" (Silverstone et al., 2003, p.19). I suggest that taking this view seriously requires us to pay more attention to the household into future studies of the interactions between digital media markets, legal frameworks and everyday consumption practices. 
Research on the media industries regularly pays attention to the market and to law. However, as we have seen in this article, the household is an active, albeit often overlooked, player in these economic configurations. The functionalist market-oriented story told by this article is that while the introduction of Netflix to the Australian market has stemmed copyright infringement it has not altered existing circumvention practices. However, we could also offer an alternative narrative that places the household at the centre of this transformation and describes a range of homes making active moral decisions about their consumption habits that go on to impact the market. The point is not to choose one or the other viewpoint, but rather to suggest that the latter view is often not explored in detail. In short, studying the home and our everyday domestic practices around digital media does not just tell us about our lives with media but also provides an often under-explored perspective on how digital media markets come to be constituted. 


\section{References}

Bird, J (2014) TV on the cheap. Choice. Available at: https://www.choice.com.au/electronicsand-technology/home-entertainment/home-entertainment-networks/articles/how-manyaustralians-watch-netflix-241114 (accessed 21 October 2016).

Bourdieu, P (1984) Distinction: A Social Critique of the Judgement of Taste. Cambridge, MA: Harvard University Press.

Church K, Weight J, Berry M, Macdonald H (2010) At Home with Media Technology. Home Cultures, 7(3): 263-86.

Dootson, P and Suzor, N (2015) The Game of Clones and the Australia Tax: Divergent Views about Copyright Business Models and the Willingness of Australian Consumers to Infringe. UNSW Law Journal, 38(1): 206 - 239.

Ewing, S, van der Nagel, E and Thomas, J (2014) CCi Digital Futures 2014: The internet in Australia. ARC Centre of Excellence for Creative Industries and Innovation, Swinburne Institute for Social Research, Melbourne.

Given J (2016) “There Will Still Be Television but I Don’t Know What It Will Be Called!”: Narrating the End of Television in Australia and New Zealand. Media and Communication, 4(3): 109-22. 
Haddon, L (2007) Roger Silverstone's Legacies: Domestication. New Media \& Society, 9(1): $25-32$.

Herd, C (2016) 'The Televisual Landscape Today. In: Arrow, M, Baker, J and Monagle, C (eds) Small Screens: Essays On Contemporary Australian Television. Melbourne: Monash University Publishing, pp. $1-19$.

Hoof, F (2016) Live Sports, Piracy and Uncertainty: Understanding Illegal Streaming Aggregation Platforms. In: Lobato, R and Meese, J (eds) Geoblocking and Global Video Culture. Amsterdam: Institute of Network Cultures, pp. 86 - 92.

House of Representatives Standing Committee on Infrastructure and Communications (2013), At what cost? IT pricing and the Australia tax. Report for The Parliament of the Commonwealth of Australia, July 2013, Canberra: Commonwealth of Australia.

Kennedy, J, Meese, J and van der Nagel, E (2016) Regulation and social practice online. Continuum: Journal of Media and Cultural Studies, 30(2): 146-157.

Kennedy J, Nansen B, Arnold M, Wilken R, Gibbs M (2015) Digital Housekeepers and Domestic Expertise in the Networked Home. Convergence: The International Journal of Research into New Media Technologies, 21(4): 408-22.

Larsson S, Wnukowska-Mtonga S, Svensson M and De Kaminski M (2014) Parallel Norms: File-Sharing and Contemporary Copyright Development in Australia. The Journal of World Intellectual Property 17(1-2): 1-5. 
Lally, E (2002) At Home With Computers. Oxford: Berg Publishers.

Leaver, T (2008) Watching Battlestar Galactica in Australia and the tyranny of digital distance. Media International Australia, 126(1): 145-154.

Lobato R and Ewing S (2014) Unlocking the geoblock: Australians embrace VPNs. The Conversation. Available at: http://theconversation.com/unlocking-the-geoblock-australiansembrace-vpns-32373 (accessed 21 October 2016).

Lobato, R and Meese, J (2016) Australia: Circumvention Goes Mainstream. In: Lobato, R and Meese, J (eds) Geoblocking and Global Video Culture. Amsterdam: Institute of Network Cultures, pp. $120-129$.

Lobato, R and Tang L (2014) The cyberlocker gold rush: Tracking the rise of file-hosting sites as media distribution platforms. International Journal of Cultural Studies 17(5): 423435.

MacNeill, K (2016). Torrenting Game of Thrones So wrong and yet so right. Convergence: The International Journal of Research into New Media Technologies, Online First, doi: 1354856516640713.

Meese J and Podkalicka A (2016) Circumvention, Media Sport and The Fragmentation of Video Culture. In: Lobato, R and Meese, J (eds) Geoblocking and Global Video Culture. Amsterdam: Institute of Network Cultures, pp. $47-85$. 
Nansen B, Arnold M, Gibbs M and Davis H (2009) Domestic orchestration: Rhythms in the mediated home. Time \& Society 18(2-3): 181-207.

Online Copyright Infringement Research (2015), Department of Communications. Available at:

https://www.communications.gov.au/sites/g/files/net301/f/DeptComms\%20Online\%20Copyr ight\%20Infringement\%20Report\%20FINAL\%20.pdf (Accessed 1 November 2016)

Consumer survey on Online Copyright Infringement 2016 (2016), Department of Communications. Available at:

https://www.communications.gov.au/sites/g/files/net301/f/online-copyright-infringement2016-final_report-accessible.pdf

Pertierra, A and Turner, G (2013) Locating Television: Zones of Consumption. London and New York: Routledge.

Reilly C (2016) Free-to-air TV channels come to mobile with Freeview app. c|net. Available at: https://www.cnet.com/au/news/free-to-air-tv-channels-come-to-mobile-with-freeviewapp/ (accessed 21 October 2016).

Roy Morgan Research (2016) Five million Australians now have Netflix; Stan and Presto are still well behind, but growing. Roy Morgan Research. Available at:

http://www.roymorgan.com/findings/6839-netflix-stan-presto-subscription-video-on-demandmay-2016-201606141025 (accessed 21 October 2016). 
Shove, E and Pantzar, M (2005) Consumers, Producers and Practices Understanding the invention and reinvention of Nordic walking, Journal of Consumer Culture 5(1): 43-64.

Silverstone, R (1991) From audiences to consumers: the household and the consumption of communication and information technologies. European Journal of Communication 6(2): $135-154$

Silverstone, R (1994) Television and Everyday Life. London: Routledge.

Silverstone, R and Hirsch, E eds. (2003) [1992] Consuming Technologies: Media and Information in Domestic Spaces. London: Routledge.

Silverstone, R, Hirsch, E and Morley, D (2003) [1992] 'Information and communication technologies and the moral economy of the household' in Silverstone, R and Hirsch, E eds. Consuming Technologies: Media and Information in Domestic Spaces. London: Routledge. Simpson C (2016) Presto Is Dead. Gizmodo. Available at: http://www.gizmodo.com.au/2016/10/presto-is-dead/ (accessed 21 October 2016) Turner, G and Tay, J (Eds) 2009 Television studies after TV: Understanding television in the post-broadcast era. London: Routledge. 